\title{
Spectrum of Pediatric Dermatoses in The Pediatric Outpatient Clinic of a Rural Teaching Hospital
}

\author{
Ambike D ${ }^{1}$, Bhavari $V^{2}$, Haribhakta $S^{3}$ Deshmukh $A^{4}$ \\ ${ }^{1}$ Dr. Deepali Ambike, Professor and Head, ${ }^{2}$ Dr. Vijay Bhavari, Associate Professor, ${ }^{3}$ Dr. Sandhya Haribhakta, \\ Associate Professor, ${ }^{4}$ Dr. Asmita Deshmukh, II MBBS Student, all authors are affiliated with Department of \\ Pediatrics, M.I.M.E.R Medical College, Talegaon Dabhade, Pune, Maharashtra, India.
}

Address for Correspondence: Dr. Vijay Bhavari, Associate Professor, Department of Pediatrics, M.I.M.E.R Medical College, Talegaon Dabhade, Pune, Maharashtra, India, E-mail: vijaybhavari20@gmail.com

\begin{abstract}
Introduction: Skin diseases in the pediatric population are common all over the world including rural and urban areas. There is variation in the pattern and presentation of Dermatoses, with eczemas being the most common skin disorder in developountries and infections and infestations in the developing countries. Aims and Objectives: i) To study the spectrum of various dermatoses in infants and children attending pediatric outpatient clinic. ii) To study the pattern of common Dermatological conditions affecting the pediatric population of different age groups. Material \& Methods: It was an observational retrospective database study of the spectrum of various dermatoses in infants and children attending pediatric outpatient clinic over past 6 months from July 2016 to December 2016. We included all patients coming with skin disorders to the pediatrics outpatient department. Results: The entire data was entered and cleaned in MS Excel before its statistical analysis. Among 2078 pediatric skin patients attending the Dermatology OPD, 597 cases were Infectious and 1481 cases were Non infectious. Males outnumbered the females. The distribution of diagnosis of dermatoses differs significantly between male and female cases studied (P-value $<0.001)$. Three most common spectrums of dermatoses were pityriasisinfections (17.5\%), Atopic dermatitis (11.4\%) and Tinea infections (10.5\%). Tinea infections were found to be highest $(36.7 \%)$ and next common was scabies (24.5\%) in Infectious variety followed by Chicken-pox / Varicella (7.7\%). Conclusion: Over all fungal infections, Atopic Dermatitis and Pytiriasis were commonest which commonly occurred in adolescents and teen age groups which could be attributed to hormonal changes, excessive sweating, and bad hygiene.
\end{abstract}

Key words: Dermatoses, Adolescents, Infectious, Noninfectious

\section{Introduction}

Dermatological conditions constitute at least $30 \%$ of all outpatient visits to pediatrician and $30 \%$ of all visits to dermatologists involve children. The incidence of skin diseases among children in various part of India has ranged from $8.7 \%$ to $38.8 \%$ in different studies usually school based surveys Because of more delicate nature of the skin of infant and children as well as contact exposure to trauma, most skin diseases of childhood are attributable to physical cause, infection and allergy. Also the disease pattern differs in a given population by different ecological factor [1].

Manuscript received: $6^{\text {th }}$ November 2017 Reviewed: $16^{\text {th }}$ November 2017

Author Corrected: $24^{\text {th }}$ November 2017

Accepted for Publication: $30^{\text {th }}$ November 2017
Skin diseases are a major health problem in pediatric age group and are associated with significant mortality. Skin diseases in the pediatric population are common all over the world including rural and urban areas [2]. Various epidemiological studies have been undertaken across the world including India to study the pattern of pediatric dermatomes.

The epidemiological data in Indian studies is based on pattern of pediatric dermatitis in school going children in both urban and rural area and in tertiary care hospitals [3]. Pediatric dermatomes require a separate view from adult dermatomes as there are important difference in clinical presentation, treatment and prognosis [4]. Studies of pediatric 
population suffering from skin diseases can play an important role in public health policy making. The aim of this study is to give an overview of the statistical study of different dermatologic diseases in infant and children in rural hospital in Mavalregion.

Cutaneous infection sare common in school going children and can spread due to intermingling with each other if not treated properly. Adele scent population inhale different spectrum of disease pattern altogether. We want to under take this project to study the spectrum man pattern of different Dermatoses in pediatric patients of different age groups.

\section{Material \& Methods}

Type of Study: Observational retrospective database study of the spectrum of various dermatoses in infants and children.

Place of Study: Pediatric Dermatology outpatient clinic.

\section{Results}

Table-1: The age distribution of the cases.

\begin{tabular}{|c|c|c|}
\hline Age Group (years) & No. of cases & \% of cases \\
\hline Less than 1 year & 66 & 3.2 \\
$1.0-5.0$ years & 283 & 13.6 \\
$6.0-10.0$ years & 285 & 13.7 \\
$11.0-15.0$ years & 531 & 25.6 \\
$16.0-18.0$ years & 913 & 43.9 \\
\hline Total & $\mathbf{2 0 7 8}$ & $\mathbf{1 0 0 . 0}$ \\
\hline
\end{tabular}

The age group distribution was $3.2 \%$ in infancy group ( $<1$ year), $13.6 \%$ in $1-5$ years age group, $13.7 \%$ in 6 10years age group, $25.6 \%$ in teens $11-15$ years age group and $43.9 \%$ in Adolescent age group.

Table-2: The sex distribution of the cases.

\begin{tabular}{|c|c|c|}
\hline Sex & No. of cases & \% of cases \\
\hline Male & 1131 & 54.4 \\
Female & 947 & 45.6 \\
\hline Total & $\mathbf{2 0 7 8}$ & $\mathbf{1 0 0 . 0}$ \\
\hline
\end{tabular}

A total of 2078 cases were studied; males were 1131 (54.4\%) and females were 947 (45.5\%).

Among 2078 pediatric skin patients attending the Pediatric Dermatology OPD, 598 cases (28.7\%) were Infectious and 1480 cases $(71.2 \%)$ were Noninfectious. The three most common spectra of Dermatoses were pytirias is infections (17.5\%), Atopic dermatitis (11.4\%) and Tinea infections (10.5\%) followed by Acne (9.1\%). 
Table-3: The distribution of dermatoses among the Infectious cases.

\begin{tabular}{|c|c|c|c|c|}
\hline Srno & Overall Diagnosis & Diagnosis of dermatoses & No. of cases & \% of cases \\
\hline 1 & Infectious & Tinea infections & 219 & 36.7 \\
2 & & Scabies & 146 & 24.5 \\
3 & Chicken pox & 46 & 7.7 \\
4 & Fungal infection & 31 & 5.2 \\
5 & Viral wart & 28 & 4.7 \\
7 & Molluscum & 18 & 3.0 \\
8 & Variecella / herpes zoster & 17 & 2.8 \\
9 & Furunculosis & 13 & 2.2 \\
10 & Folliculitis & 7 & 2.0 \\
11 & Hansen & 7 & 1.2 \\
12 & & Candidiasis /balanitis/vaginitis & 6 & 1.2 \\
13 & Measles & 24 & 1.0 \\
\hline & Others & $\mathbf{5 9 8}$ & 4.0 \\
\hline
\end{tabular}

Tinea infections were found to be highest $(36.7 \%)$ and next common was scabies $(24.5 \%)$ in Infectious variety followed by Chicken -pox / Varicella (7.7\%). Fungal Infections was (5.2\%), viral warts (4.7\%) andVaricella Zoster $2.8 \%$.

Table-4: The distribution of dermatoses among the Noninfectious cases.

\begin{tabular}{|c|c|c|c|c|}
\hline 1 & \multirow[t]{23}{*}{ Non-Infectious } & Pityriasis infections & 364 & 24.6 \\
\hline 2 & & Atopic dermatitis & 236 & 15.9 \\
\hline 3 & & Acne & 189 & 12.8 \\
\hline 4 & & Vitiligo & 78 & 5.3 \\
\hline 5 & & Insect bite & 61 & 4.1 \\
\hline 6 & & Xerosis & 54 & 3.6 \\
\hline 7 & & Impetigo & 50 & 3.4 \\
\hline 8 & & Dandruff & 36 & 2.4 \\
\hline 9 & & Eczema & 35 & 2.4 \\
\hline 10 & & M.contogiosum & 33 & 2.2 \\
\hline 11 & & Seborrheic dermatitis & 32 & 2.2 \\
\hline 12 & & Hair fall & 27 & 1.8 \\
\hline 13 & & Urticaria & 26 & 1.8 \\
\hline 14 & & Steroid induced acne & 24 & 1.6 \\
\hline 15 & & Alopecia areata & 22 & 1.5 \\
\hline 16 & & Keratolysis & 14 & 0.9 \\
\hline 17 & & Contact dermatitis & 10 & 0.7 \\
\hline 18 & & Psoriasis & 10 & 0.7 \\
\hline 19 & & Keloid & 8 & 0.5 \\
\hline 20 & & Erythroderma & 7 & 0.5 \\
\hline 21 & & Corn & 6 & 0.4 \\
\hline 22 & & Melasma & 5 & 0.3 \\
\hline 23 & & Others & 154 & 10.4 \\
\hline & & Total & 1480 & $\overline{100.0}$ \\
\hline
\end{tabular}

Among the Non- Infectious spectrum, Pytiriasis was maximum (24.6\%) and next in the order was Atopic Dermatitis (15.9\%) followed by Acne (12.8\%). 
Table-5: The distribution of overall diagnosis of dermatoses according to age.

\begin{tabular}{|c|c|c|c|c|c|c|c|}
\hline & \multicolumn{2}{|c|}{ Infectious } & \multicolumn{2}{c|}{ Non-Infectious } & \multicolumn{2}{c|}{ Total } & P-value \\
\hline $\begin{array}{c}\text { Age Group } \\
\text { (years) }\end{array}$ & $\mathbf{n}$ & $\mathbf{\%}$ & $\mathbf{n}$ & $\mathbf{0}$ & $\mathbf{n}$ & $\%$ & \\
\hline Less than 1 year & 12 & 18.2 & 54 & 81.8 & 66 & 100.0 & $0.001^{* * *}$ \\
$1.0-5.0$ years & 75 & 26.5 & 208 & 73.5 & 283 & 100.0 & \\
$6.0-10.0$ years & 71 & 24.9 & 214 & 75.1 & 285 & 100.0 & 100.0 \\
$11.0-15.0$ years & 131 & 24.7 & 400 & 75.3 & 531 & 100.0 & \\
$16.0-18.0$ years & 308 & 33.7 & 605 & 66.3 & 913 & 100.0 & \\
\hline Total & $\mathbf{5 9 7}$ & $\mathbf{2 8 . 7}$ & $\mathbf{1 4 8 1}$ & $\mathbf{7 1 . 3}$ & $\mathbf{2 0 7 8}$ & \\
\hline
\end{tabular}

Values are $\mathrm{n}$ (\% of cases). P-value by Chi-Square test. $\mathrm{P}$-value $<0.05$ is considered to be statistically significant. $* * *$ P-value $<0.001$ (Highly Significant).

The distribution of diagnosis of dermatoses differs significantly across various age groups of the cases studied (Pvalue $<0.001)$. Non- Infectious cases were more over all in all age groups. $(81.8 \%)$ in infancy than Infectious $(18.2 \%), 73.5 \%$ in $1-5$ years age group, $75.1 \%$ in $6-10$ years age group, $75.5 \%$ in $11-15$ years age group and $66.3 \%$ in $16-18$ years age group.

Table-6: The distribution of overall diagnosis of dermatoses according to sex.

\begin{tabular}{|c|c|c|c|c|c|c|c|}
\hline & \multicolumn{2}{|c|}{ Infectious } & \multicolumn{2}{c|}{ Non-Infectious } & \multicolumn{2}{c|}{ Total } & P-value \\
\hline Sex & $\mathbf{n}$ & $\mathbf{\%}$ & $\mathbf{n}$ & $\mathbf{\%}$ & N & \% & \\
\hline Male & 367 & 32.4 & 764 & 67.6 & 1131 & 100.0 & $0.001^{* * *}$ \\
Female & 230 & 24.3 & 717 & 75.7 & 947 & 100.0 & \\
\hline Total & $\mathbf{5 9 7}$ & $\mathbf{2 8 . 7}$ & $\mathbf{1 4 8 1}$ & $\mathbf{7 1 . 3}$ & $\mathbf{2 0 7 8}$ & 100.0 & \\
\hline
\end{tabular}

Values are $\mathrm{n}$ (\% of cases). P-value by Chi-Square test. $\mathrm{P}$-value $<0.05$ is considered to be statistically significant. $* * * \mathrm{P}-$ value $<0.001$ (Highly Significant).

The distribution of diagnosis of dermatoses differs significantly between male and female cases studied (Pvalue $<0.001)$. Noninfectious skin disorders were more prevalent than Infectious in in both sexes. $67.6 \%$ noninfectious in males as to only $32.4 \%$ cases were Infectious. Similarly, $75.7 \%$ were noninfectious in females as compared to only $28.7 \%$ infectious.

\section{Discussion}

The present study brings into focus the spectrum of pediatric Dermatoses encountered in Maval area in Pune District as our Hospital being a referral Centre. There is paucity of epidemiological data on Pediatric Dermatoses, hence this study taken up.

Among 2078 pediatric skin patients attending the Pediatric Dermatology OPD, Males (54.4\%) outnumbered the females in our study (45.6\%) similar to study in Western Nepal [6]. The distribution of diagnosis of dermatoses differs significantly between male and female cases studied (P-value $<0.001$ ).
About 597(28.7\%) cases were Infectious and 1481(71.2\%) cases were Noninfectious. This shows that Noninfectious skin diseases outstripped in our study which was similar to studies conducted by Vishal et al [7] where it was $52.65 \%$ and in many other studies where it varied between $40.9 \%$ to $58.7 \%$ [8-10]. The reason behind this may be increased awareness for non- infectious or allergic diseases due to Patient education and counseling.

Our study revealed the incidence of Infectious skin diseases to be only $28.7 \%$ for which we need to study the reasons behind the non-referral which is in 
contrast to some other studies have reported higher incidence of Infectious skin diseases like in the Libya study by Safa et al which was (42\%). Inother studies, by Grover et al, Sayal et al and Dayal et al [11-13] the incidence of Infectiousskin diseaseswas varying from $59.1 \%$ to $89.7 \%$. The distribution of diagnosis of dermatoses differs significantly across various age groups of the cases studied ( $\mathrm{P}$ value $<0.001)$. The incidence of Non- Infectious cases were more over all in all age groups than Infectious variety, $(81.8 \%)$ in infancy, $73.5 \%$ in $1-5$ years age group, $75.1 \%$ in 6-10 years age group, $75.5 \%$ in $11-15$ years age group and $66.3 \%$ in $16-18$ years age group. Similar observations were found in Mexican study by Blanca Rosa et al [14]. Our hospital being a major referral center from the peripheral Maval area, the awareness on common Dermatological conditions like Atopy and Allergies (Non- Infectious) in children and Acne (NonInfectious) in Teenagers may be more which could be the reason for same.

The three most common spectrums of Dermatoses were pityriasis infections (17.5\%), Atopic dermatitis $(11.4 \%)$ and Tinea infections (10.5\%). This observation was similar to many studies like Mexico study [12] and Libya study [13].

Among the Infectious skin diseases spectrum, Tinea infections were found to be highest $(36.7 \%)$ in our study as in the Libya study [15] which was $20 \%$ incidence. Next common was scabies $(24.5 \%)$ which was very similar to the Pondicherry study by Kumar et al and a Himachal study [16-17]. Reason is selfexplanatory as both are highly contagious. Chickenpox / Varicellawas observed in $7.7 \%$ in our study. However, Varicella infection was not reported in many studies. The reason behind both observations could be direct indoor admission for Varicella.

Among the Non- Infectious spectrum, Pityriasis was common $(24.6 \%)$ and next in the order was Atopic Dermatitis $(15.9 \%)$ followed by Acne $(12.8 \%)$ in our study. Higher incidence of Pityriasis could be explained due to dietary factors deficiency like zinc and trace elements. This was similar to the Turkey study [18] where Pityriasis was $18.3 \%$, and Acne was $9.6 \%$. However, they [18] had lesser prevalence of Atopic Dermatitis (1.6\%) as this study was conducted only in primary school children and we covered all age groups from infancy to Adolescents which explains the reason behind Atopy and Acne.

\section{Conclusion}

In conclusion, our study shows that the prevalence and diversity of skin disorders varies from one area / country from another. The most common skin disorders found in our study were simple and could be cured easily like Taenia, Pityriasis, Atopic Dermatitis and Acne. Awareness of parents should be raised in terms of early referral to experts for these commonly treatable diseases. This study will help in education of the rural population regarding prevention of skin disorders related to hygiene, sanitation and dietary factors.

Implications: This study will help in education of the rural population regarding prevention of common skin disorders related to hygiene, sanitation and dietary factors like Taenia, Pityriasis, Atopic Dermatitis and Acne. Preventive and curative health services should be provided especially for adolescent skin diseases which is more prevalent in our study.

\section{Declaration}

Contribution of Authors: Conception and Design: DA and VB, Planning and Conduction of Study: VB \& DA, Data Collection and Supervision: $\mathrm{AD}, \mathrm{VB}$ and $\mathrm{SH}$, Analysis and Interpretation: VB, $\mathrm{AD}$ and DA.

\author{
Abbreviations: OPD (Outpatient Department). \\ Funding: Nil, Conflict of interest: None initiated, \\ Perission from IRB: Yes
}

\section{References}

1. Jawade S, Chugh V, Gohil S, Mistry A and Umrigar D. A. Clinico-Etiological Study of Dermatoses in Pediatric Age Group in Tertiary Health Care Center in South Gujarat Region. Indian Journal of Dermatology; 2015 Nov-Dec; 60(6):635. DOI: $10.4103 / 0019-5154.169147$.

2. Sharma S, Bassi R, Manmeet Kaur S. Epidemiology of dermatoses in children and adolescents in Punjab, India. Journal of Pakistan Association of Dermatologists;2012;22 (3):224-229.

3. Jain N, Khandpur S. Pediatric dermatoses in India: Indian Journal of Dermatology, Venereology, and Leprology.Vol. 76, No. 5, September-October, 2010, 76(5) 451-454.DOI:10.4103/0378-6323.69034 
4. Shrestha R, Shrestha D, Dhakal AK, Shakya A, Shah SC, Shakya H. Spectrum of pediatric dermatoses in tertiary care center in Nepal. Nepal Med Coll J. 2012 Jun;14(2):146-8.

5. Karthikeyan K, Thappa D, Jeevankumar B. Brief Report. Pattern of Pediatric Dermatoses in a Referral Center in South India. Indian Pediatrics 2004 April (41): 374-377

6. Poudyal Y, Ranjit A, Pathak S, Chaudhary N. Pattern of Pediatric Dermatoses in a Tertiary Care Hospital of Western Nepal. Dermatology Research and Practice.2016; 1-5

7. Giri V, Giri O, Gupta S, Kanodia S. ClinicoEpidemiological Profile of Inflammatory and Infective Skin Diseases In A Tertiary Care Centre In East India. International Journalof Medical Research and Health Sciences: 2014: 3(4): 892-896. DOI:10. 5958/ 2319-5886.2014.00021.6

8. Das KK. Pattern of dermatological diseases in Gauhati medical college and hospital Guwahati. Indian J DermatolVenereol Leprol 2003;69: 16-18.

9. Devi T, Zamzachin G, "Pattern of skin diseases in Imphal. Indian J Dermatolgy, 2006; 51: 149-50.

10. Gangadharan C, Joseph A, Sarojini PA. Pattern of Skin Diseases in Kerala. Indian $\mathrm{J}$ Dermatol Venereol Leprol. 1976 Mar-Apr;42(2):49-51.

11. Grover S, Ranyal RK, Bedi MK. A cross section of skin diseases in rural Allahabad. Indian $\mathrm{J}$ Dermatol. 2008;53(4):179-81. doi: 10.4103/00195154.44789
12. Sayal SK, Das AL, Gupta CM. Pattern of skin diseases among civil population and armed forces personnel at Pune. Indian J Dermatol Venereol Leprol. 1997 Jan-Feb;63(1):29-32.

13. Dayal SG, Gupta GD. A Cross Section of Skin Diseases in Bundelkhand Region, UP. Indian J Dermatol Venereol Leprol. 1977 Sep-Oct; 43 (5): $258-261$

14. Blanc Rosa Del Pozzo- Magana, Aljandro Lazo - Langner, et al. International Scholarly Research Network ISRN Dermatology. 2012: Article ID 351603: 1-5. DOI:10.5402/2012/351603

15. Safa Suleman Elfaituri. Indian Journal Of Pediatric Dermatology: April-June 2015; 16 (2); 6471. DOI: $10.4103 / 2319-7250.152125$.

16. Sharma NL, Sharma RC. Prevalence of dermatologic diseases in school children of a high altitude Tribal Area of Himachal Pradesh. Indian Journal Dermatol Venereol Leprol 1990: 56; 375376

17. Kumar V, Garg BR, Baruah MC. Prevalence of Dermatological Diseases in School Children in a Semi- Urban Area in Pondicherry. Indian $\mathrm{J}$ Dermatol Venereol Leprol. 1988 Nov-Dec; 54 (6): 300-302.

18. Bilal Sula, Derya Uçmak, Günay Saka, Sedat Akdeniz, Engin Yavuz, Yunus Yakut, Evrim Arslan, Hamza Aktaşş, Mehmet Yıldız, Sibel Yolbir, and RukenAzizoğlu: Prevalence of skin disorders among primary school children in Diyarbakir, Turkey : Arch Argent Pediatr 2014;112 (5): 434 - 438 .

\section{How to cite this article?}

Ambike D, Bhavari V, Haribhakta S Deshmukh A. Spectrum of Pediatric Dermatoses in The Pediatric Outpatient Clinic of a Rural Teaching Hospital. Int J Pediatr Res. 2017;4(11):666-671. doi:10.17511/ijpr.2017.i11.06. 